Available online at GSC Online Press Directory

GSC Biological and Pharmaceutical Sciences

e-ISSN: 2581-3250, CODEN (USA): GBPSC2

Journal homepage: https://www.gsconlinepress.com/journals/gscbps

(RESEARCH ARTICLE)

\title{
Effect of artemether on the mechanical activities of isolated smooth muscles of non- pregnant uterus and ileum in mice and wistar rats
}

Tologbonse Adedayo Adedoyin ${ }^{1}$, Essien Grace Emmanuel ${ }^{1,}{ }^{*}$, Onwuka Amanda Ngozi ${ }^{1}$, Mbagwu H.O.C ${ }^{1}$ and Unekwe Prince $\mathrm{C}^{2}$

${ }^{1}$ Department of Pharmacology and Toxicology, University of Uyo, Uyo-Akwa ibom State, Nigeria.

${ }^{2}$ Department of Pharmacology and Therapeutics, College of Health Sciences, Nnamdi Azikiwe University, Nnewi, Anambra State, Nigeria.

Publication history: Received on 10 June 2020; revised on 19 June 2020; accepted on 21 June 2020

Article DOI: https://doi.org/10.30574/gscbps.2020.11.3.0173

\begin{abstract}
This study investigated the effect of artemether on smooth muscle contractility to drugs in non-pregnant female wistar rats. The effect of artemether $\left(2.1 \times 10^{-6}\right.$ to $\left.2.1 \times 10^{-2}\right)$ on isolated uterine and ileum muscle strips was studied using sixteen (16) mature female Wister rats $(160-190 \mathrm{~g})$ mounted on organ baths. The study further investigated the effect of artemether on sub-acute histopathological examination of the ileum using standard in vivo procedures in mice models. Data obtained from the study were represented on table, graph and photomicrographs. The results of this study revealed that artemether $\left(2.1 \times 10^{-6}\right.$ to $\left.2.1 \times 10^{-2}\right)$ alone did not produce contractile responses, but caused significant inhibition on contractile responses induced by acetylcholine $\left(4 \times 10^{-5}\right.$ to $\left.4 \times 10^{-1} \mathrm{M}\right)$ on isolated ileal smooth muscle tissue in rats in a dose dependent manner $(\mathrm{p}<0.05)$; also artemether significantly inhibited the contractions induced by oxytocin $8 \times 10^{-10}$ to $1 \times 10^{-6}$ I.U.) and barium chloride ( $8 \times 10^{-6}$ to $\left.8 \times 10^{-2} \mathrm{mg} / \mathrm{ml}\right)$ on uterine smooth muscle strips in rats in a dose dependent manner; with Emax of $13.5 \pm 0.2$ and $12.6 \pm 0.4 \mathrm{~mm}$ respectively, all the observed results were independent of tissue species variation. ( $\mathrm{p}<0.05-0.01)$. This study revealed that artemether exhibited no adverse effect on the non-pregnant uterus and the rat ileum, hence its safety in the treatment of malaria, as recommended by the World Health Organization.
\end{abstract}

Keywords: Artemether; Agonists; Contractility; Plasmodium berghei berghei; Smooth muscles.

\section{Introduction}

Malaria is a tropical disease, which is transmitted by anopheles mosquitoes. World malaria reports indicate that there were 219 million cases of malaria globally in 2019 and 438,000 malaria deaths [1]. Plasmodium falciparum is the most clinically significant causative organism and has been reported to demonstrate an unusual propensity to acquire resistance to antimalarial therapy [2] [3]. Currently artemisinin and its derivatives (artemether, arteether, artesunate and dihydroartemisinin) present a new series of antimalarial drugs with a high level of activity against chloroquine resistant strains of malaria parasite [4].

The World Health Organization currently recommends artemisinin-based combination therapy (ACT) as first line treatment for uncomplicated malaria, which has also resulted in an increase in the use of artemisinins [5]. Artemisinins generally have good permeability; artemether is lipid -soluble and poorly water-soluble [6]. Furthermore, treatment of malaria with artemisinins has been implicated with various adverse effects including that of muscle weakness, malaise, vomiting, diarrhea etc. Some of these effects are on smooth muscles activities.

\footnotetext{
${ }^{*}$ Corresponding author: Essien Grace Emmanuel
} 
Research work on the mechanical activity of muscles on ancient antimalarials such as chloroquine, mefloquine, quinine in animal models had been carried out extensively [7][8][9][10][11]. On the contrary, few studies so far have been carried out on the effect of Artemisinin derivatives on muscle contractility [12]. Studies were also done on the effects of artemether on uterine muscle. The effect of artesunate on guinea pig ileum was also investigated [13].

This present work was designed to investigate the effect of artemether on isolated smooth muscle contractility of ileum and uterine strips with a view of elucidating the probable mechanism of the drug action and to ascertain the safety profile of artemether.

\section{Materials and methods}

\subsection{Experimental Animals}

The research was carried out using matured home bred male and female mice and female albino rats of wistar strain (weight - matched). They were all healthy, hence diseases-free. Thirty (30) mice (18-23 g), twenty four (24) rats (160$190 \mathrm{~g}$ ) were purchased from the animal house of the department of Pharmacology and Toxicology University of Uyo. The wistar rats were used for in vitro organ bath study, while the mice were utilized for the in vivo models and were divided randomly into groups according to their body weights.

The animals were fed with a standard laboratory feed pellet- growers mash from agro feeds Limited, Lagos and provided distilled water for drinking ad libitum. All animals were well acclimatized having been kept in clean metabolic polypropylene/wooden cages with laboratory-grade pine shavings as beddings, contained in well-ventilated house and maintained under standard conditions (temperature: $25 \pm 3{ }^{\circ} \mathrm{C}$; photoperiod: 12-h natural light and 12-h dark cycle; humidity: 35-60\%) for two weeks prior to drug treatments.

The Physiological solutions used in this study were-Tyrode solution and De jalon solution. All chemicals were of high analytical grade and were dissolved in either deionized distilled water or normal saline at the required concentrations.

\subsection{Preparation of Drugs/ Posology}

The completely homogenous test drug - Arthemeter was administered to all the animals in the test groups, with the aid of 23G stainless steel oropharyngeal cannula.

The method of calculation of volume $(\mathrm{ml})$ of the drug to be given to each animal is as follows:

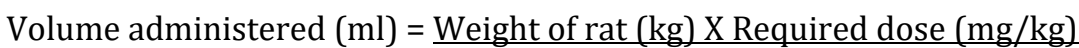

\section{Concentration of the drug}

The doses used for the in vivo studies were determined from data derived from previously established dosage in similar studies-on the effect of Artemisinin-Based Combination therapy in wistar albino rats which suggested treatment dose of between $3 \mathrm{mg} / \mathrm{kg}-6 \mathrm{mg} / \mathrm{kg}$ of Body weight [14].

\subsection{Parasite inoculum preparation}

The method of Peters [15] as described by Udobang [16] was adopted. Each mouse that was used in the in vivo experiment was inoculated intraperitoneally with $0.2 \mathrm{ml}$ of infected blood containing about $1 \times 10^{7}$ Plasmodium berghei berghei parasitized erythrocytes. In order to achieve this, the parasitized blood donor with high parasitaemia was obtained by first anaesthetizing the mouse with chloroform, and through cardiac puncture blood was collected with the aid of sterile syringe and heparinized bottles. The percentage parasitaemia was determined by counting the number of parasitized red blood cells against the total number of red blood cells.

\subsection{Grouping of Animals for in vivo Study}

The mice were divided into two groups for the in-vivo experiment. The first set served as the Control group - the mice received only distilled water (no drug treatment), and the second group consisted of the test group animals.

The test group animals were demarcated into three (3) sub-groups containing four(4) mice per group infected with Plasmodium berghei berghei ; this order was followed for the three sets of drug treatments- i.e. artemether 2.0, 3.0 and $5.0 \mathrm{mg} / \mathrm{kg}$ for low, moderate and high doses regimen respectively. 
The animals in the control groups were also divided into 3 subgroups; For -1. Non-infected/ Non-treated mice, 2 . Noninfected /Treated mice, 3. Infected mice /Non-treated according to the dosage regimens respectively. At the close of all treatment exposures, animals were sacrificed under urethane anaesthesia and by cervical dislocation. All drugs were given twice daily via oral route for five (5) consecutive days adding up to 120 hours. The animals of all the groups were observed for 2 days post administration. The animals were fasted overnight and sacrificed on the $8^{\text {th }}$ day. The mice were also assessed for the integrity of muscles using standard histological tissues staining procedures.

\subsection{Histopathological Studies and Collection of samples}

Samples were collected in the in vivo experiment after treatment as follows: clear incisions were made into the abdominal cavity of the mice up till the border near the tail of the rats. Fresh ileum, uterus, and portion of large intestine were removed from the rats and immediately fixed in $10 \%$ formalin in specimen containers for 3 days (72 hours). These organs were cut laterally and longitudinally to examine the internal structure as described by Yakubu[17].They were processed for histological evaluation by a pathologist in the University of Uyo Teaching Hospital, Uyo, Nigeria.

\subsection{Experimental procedures in vitro animal models}

This study was carried out using standard experimental procedures as described by Unekwe [18], Nwafor[19] which were applicable in the use of Organ bath with a slow moving kymograph, a basic instrument for measuring muscle tension. The organ bath was properly washed with distilled water and filled with appropriate physiological solutions.

A vertical strand of isolated muscle tissue of $2 \mathrm{~cm}$ was picked gently using forceps; needle and white thread was passed through the tissue and tied through the arm of the frontal lever to the tissue holder. The tissue holder was then placed in the tissue organ bath. The tissue was observed closely for the contractile response in the Dejallon's or Tyrodes solution alone; It was allowed to stabilize for about thirty (30) to sixty (60) minutes before investigation commenced.

Isolated muscle preparations from mice experimental animal models were used for this study:

- Isolated smooth muscle preparations e.g. isolated rat ileum and uterine muscles.

- Isolated smooth muscle preparations were obtained from the digestive and reproductive organs of the mice.

\subsection{Recordings of Contractile Responses against the Concentration of the Acetylcholine}

The methods as described by Unekwe, [11] were adopted. A vertical strand of isolated ileal smooth muscle tissue of about $2 \mathrm{~cm}$ was gently picked using forceps; needle and white thread was passed through the tissue and tied through the arm of the frontal lever to the tissue holder. After equilibrium, the concentration response test to acetylcholine alone at a concentration of $4 \times 10^{-6}$ to $10^{-3} \mathrm{M}$ was conducted separately before the addition of artemether. The least dose $\left(10^{-6} \mathrm{M}\right)$ was added first to the fluid bathing the tissues and the effect was observed for $0.5-2$ minutes and this was followed by 2-3 washings, after which the next higher dose of the agonist was added and the procedure was repeated for about 5 doses of the agonist.

\subsection{Recordings of Contractile Responses against the Concentration of the Oxytocin}

The methods as described by [18][19][20] were adopted. Before the concentration response tests to oxytocin, the organ bath was set up and the equilibration time in e case was 30 - 60 minutes during which time the tissue preparation immersed in Dejallon,s solution, was washed several times till the normal rhythmicity of the pendular movement become steady.

\subsection{Contractile Responses against the Concentration of the other Agonists}

Concentration response tests to potassium chloride and barium chloride were also conducted separately before the addition of Artemether. The initial observations with agonist alone served as control values, which were used to compare the effect of artemether on agonist - induced contractions.

For graded dose - response relationships, a specified dose of potassium chloride (KCI) or barium chloride (BacI 2 ) were added to the fluid bathing the tissues and the effect was observed for 0.5-2 minutes and this was followed by 3-5 washings, after which the next higher dose of the agonist was added and the procedure was repeated for about 5 doses of the agonist. The interval between successive doses was 5-10 minutes. 


\subsection{Recordings of contractile responses against the concentration of artemether alone}

In another set of experiments, the tissue was pretreated for about 5-15 minutes with artemether $\left(2.1 \mathrm{x} 10^{-6} \mathrm{~g} / \mathrm{ml}\right)$ and the whole procedure was repeated as described for acetylcholine. In each case threads were attached to the bottom of each piece of muscles; one thread was tied to the aerator hook and the other to a transducer /frontal writing ever. The lever was balanced by appropriate load (e.g plasticine) of about $0.5-1.0 \mathrm{~g}$ which was applied to the lever to maintain vertical tension as described by [18][20].

\subsection{Ethical Consideration}

All the animals received humane care and the study protocols were designed to comply with the Faculty of Pharmacy, University of Uyo ethical committee's guidelines for use of laboratory animals. Clearance was obtained in line with the 'Principle of Laboratory animal care' (of National Institute of Health-NIH Publication No. 85-123; 1996) guidelines [21].

\subsection{Statistical Analysis}

The results of this study were expressed as Mean+SEM and presented based on statistical computation using one way analysis of variance test (ANOVA) and by Student t- test.

\section{Results}

The result of this study shows that artemether at a concentration of $2.1 \times 10^{-6}$ to $2.1 \times 10^{-2} \mathrm{~g} / \mathrm{ml}$ produced no significant contractile response on the isolated smooth muscles being investigated within 30-45 minutes of drug contact in the organ bath containing the appropriate physiological solution.

\subsection{Effect of artemether on oxytocin induced contraction in non-pregnant uterine muscle strip in rat models}

Artemether alone at a concentration of $2.1 \times 10^{-2} \mathrm{~g} / \mathrm{ml}$ produced no contractile responses on the isolated uterine muscle strip within 30 to 45 minutes of drug contact in the organ bath containing Dejalon's solution. The same drug at a concentration of $2.1 \times 10^{-6}$ to $2.1 \times 10^{-2} \mathrm{~g} / \mathrm{ml}$ significantly antagonizes the contraction induced by oxytocin at concentration of $8 \times 10^{-10}$ to $8 \times 10^{-6}$ I.U (Table 1 ).

Table 1 Effect of Artemether on Oxytocin induced contractions in isolated uterine strip in wistar rat model

\begin{tabular}{|c|c|c|c|c|c|c|c|}
\hline \multirow[b]{2}{*}{$\begin{array}{l}\text { FBC Oxytocin (I.U) } \\
\text { Control }\end{array}$} & \multirow[b]{2}{*}{$-\log$} & & & \multicolumn{3}{|c|}{$\begin{array}{l}\text { Responses of artemether on } \\
\text { induced contractions. }\end{array}$} & \multirow[t]{2}{*}{ oxytocin } \\
\hline & & \multicolumn{2}{|c|}{$\begin{array}{l}* \quad \text { Maximum \% of max } \\
\text { height }(\mathrm{mm})\end{array}$} & $\begin{array}{l}\text { FBC } \\
\text { artemethe } \\
(\mathrm{g} / \mathrm{ml})\end{array}$ & $\begin{array}{l}\text { of-Log } \\
\text { er (M) }\end{array}$ & $\begin{array}{l}* \quad \text { Maximum } \\
\text { height }(\mathrm{mm})\end{array}$ & \\
\hline $8.0 \times 10^{-10}$ & 9.1 & $8.0 \pm 0.9$ & $59 \pm 1$ & $2.1 \times 10^{-6}$ & 5.7 & $7.2 \pm 0.4$ & \\
\hline $8.0 \times 10^{-9}$ & 8.1 & $7.9 \pm 0.3$ & $58 \pm 3$ & $2.1 \times 10^{-5}$ & 4.7 & $7.2 \pm 0.7$ & \\
\hline $8.0 \times 10^{-8}$ & 7.1 & $8.2 \pm 0.1$ & $61 \pm 1$ & $2.1 \times 10^{-4}$ & 3.7 & $7.0 \pm 0.3^{*}$ & \\
\hline $8.0 \times 10^{-7}$ & 6.1 & $10.4 \pm 0.5$ & $77 \pm 5$ & $2.1 \times 10^{-3}$ & 2.7 & $8.3 \pm 0.2^{*}$ & \\
\hline $8.0 \times 10^{-6}$ & 5.1 & $13.5 \pm 0.2$ & $100 \pm 2$ & $2.1 \times 10^{-2}$ & 1.7 & $4.1 \pm 0.2^{*}$ & \\
\hline
\end{tabular}

\subsection{Effect of Artemether on acetylcholine induced contraction on rat ileum}

Arteemether at a concentration of $2.1 \times 10^{-2} \mathrm{~g} / \mathrm{ml}$ significantly antagonizes the contraction induced by acetylcholine at concentration of $4 \times 10^{-6}$ to $4 \times 10^{-3} \mathrm{M}$. ${ }^{*} \mathrm{P} \leq 0.05$, when compared to control. (Figure 1 and Figure 3 ) 


\subsection{The Effect of Artemether (ARTM) on Muscle tissues in Mice}

Administration of artemether ( $5 \mathrm{mg} / \mathrm{kg}, 3 \mathrm{mg} / \mathrm{kg}$ and $2 \mathrm{mg} / \mathrm{kg}$ of body weight) in mice for 5 days in non-infected / non-treated mice ,infected/ treated mice and in infected/non- treated mice did not produce any significant effect on the integrity of the smooth muscles, irrespective of the dosage regimens administered in this study (Figure 4 -Figure 6).

Table 2 Effect of Artemether alone relative to barium chloride induced contractions in isolated uterine strip in wistar rat model

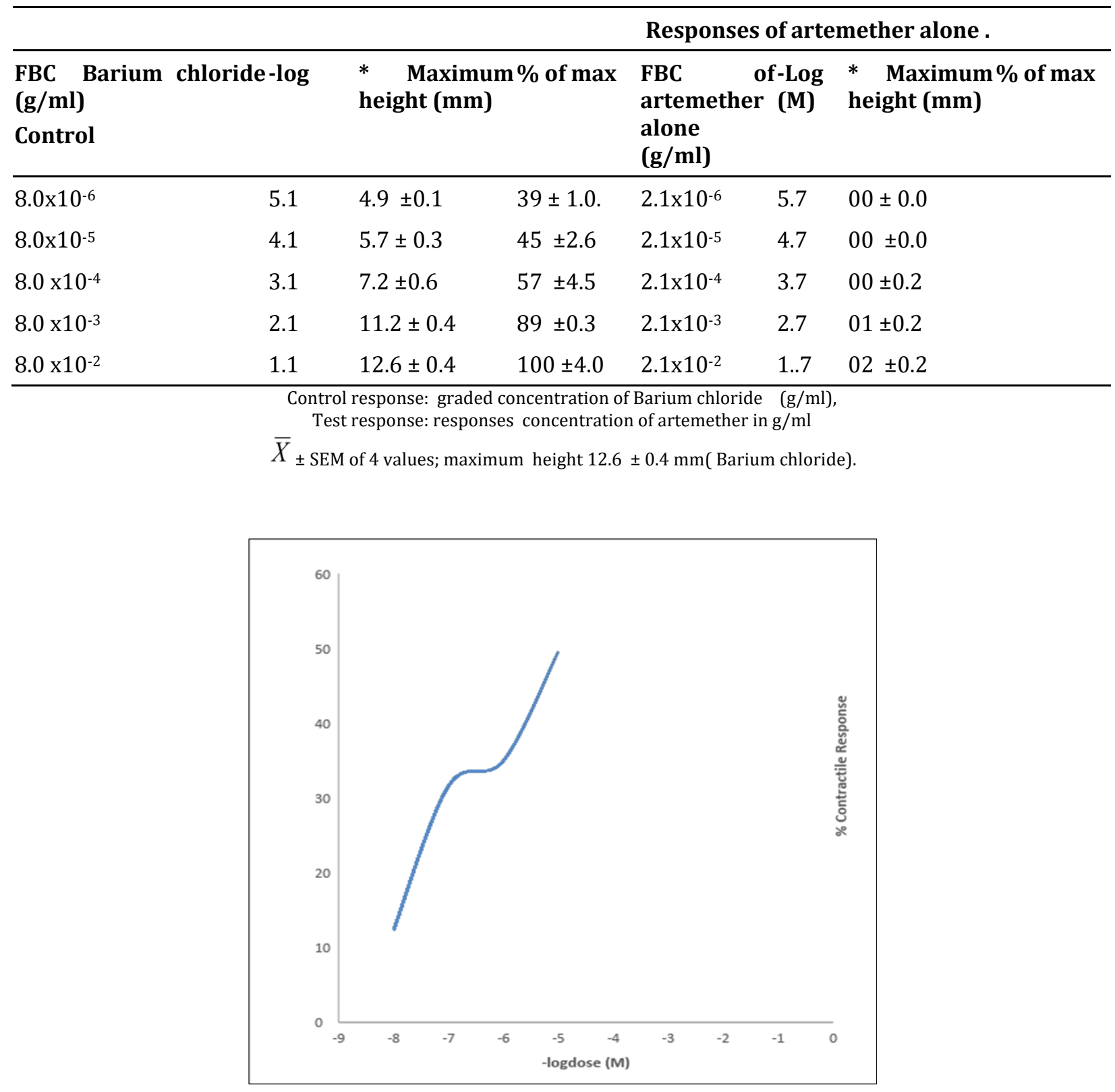

Figure 1 Effect of Acetylcholine on isolated rat ileum (control drug). 
Tologbonse et al. / GSC Biological and Pharmaceutical Sciences, 2020, 11(03), 145-154

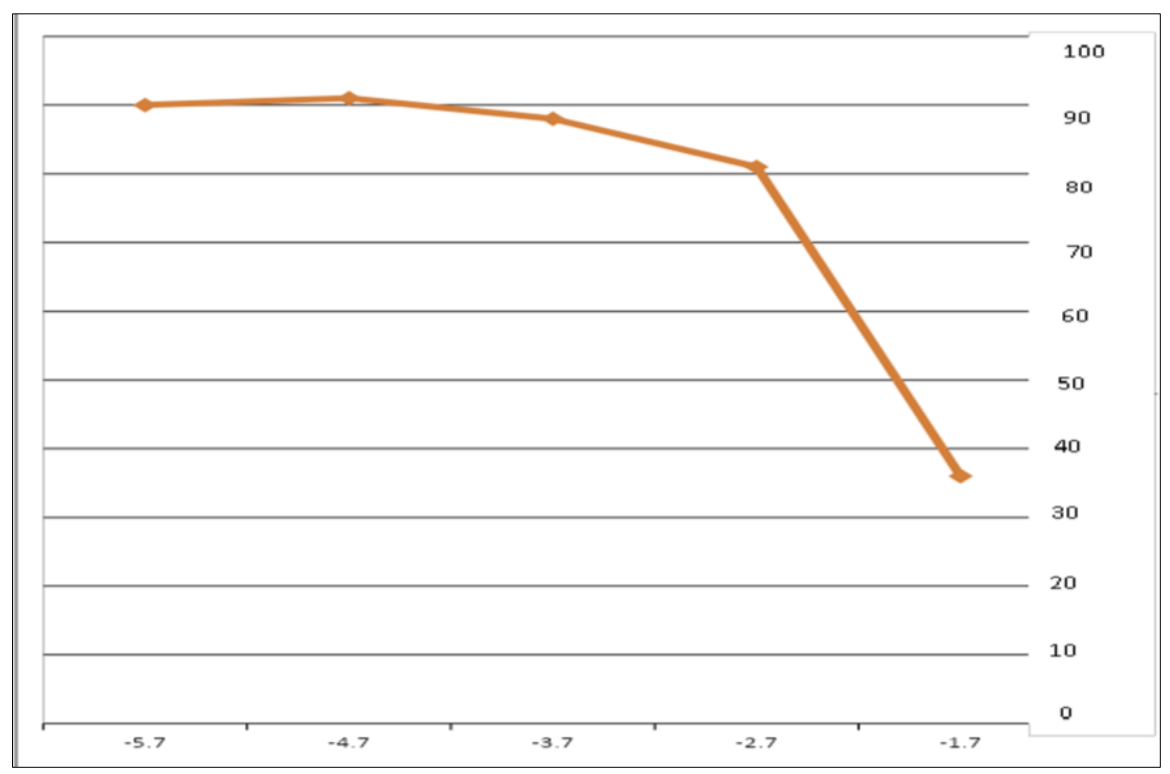

Figure 2 The effect of artemether on oxytocin induced contraction on the uterus of non-pregnant.

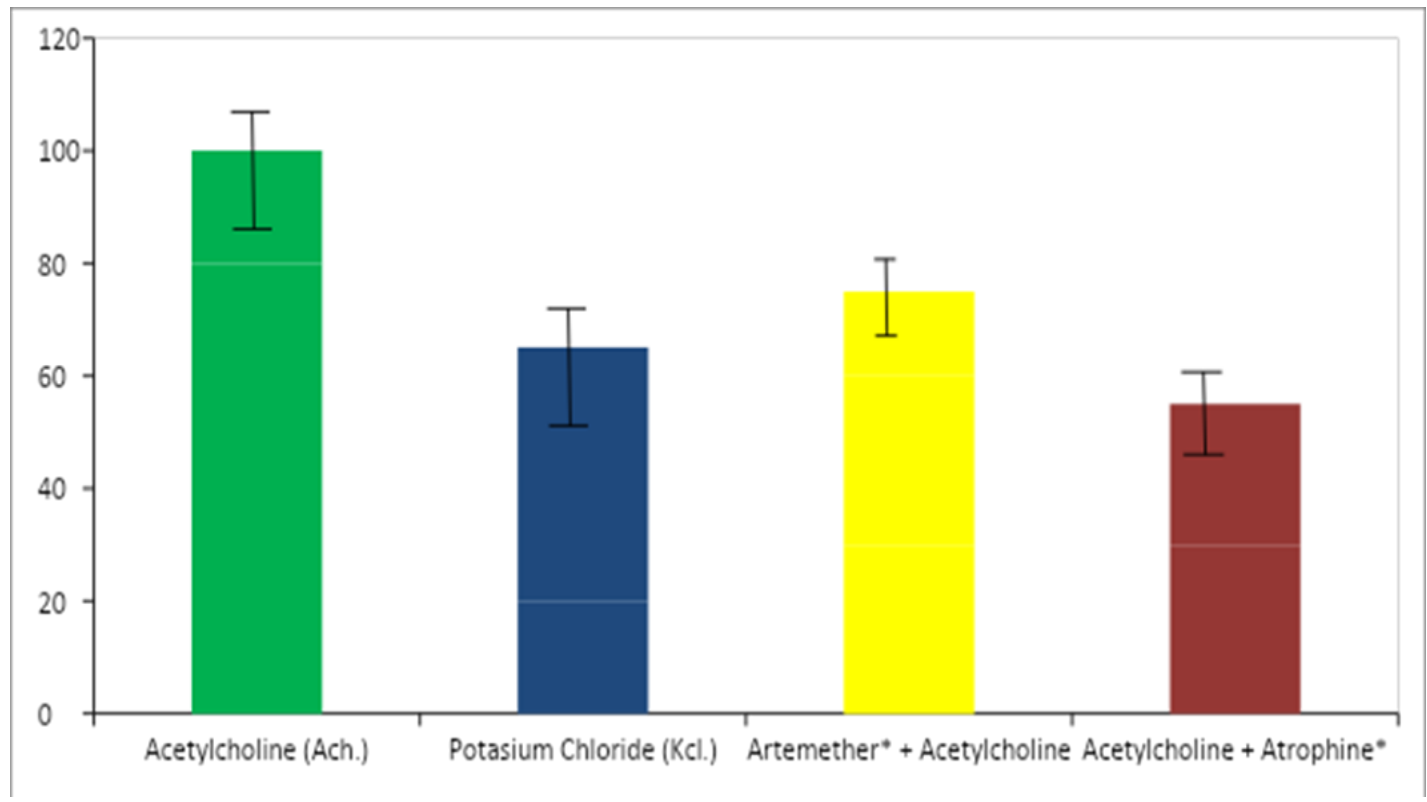

Figure 3 Bar chart showing selected maximum responses of some agonists / antagonist and artemether( ART.) in ileum of rat model. Ach. (4 x 10-6M), Emax. $=23 \pm 0.4,{ }^{*} \mathrm{P} \leq 0.05$

\subsection{The effect of arthemeter on muscle tissues in mice}

Administration of Arthemeter ( $6 \mathrm{mg} / \mathrm{kg}$ and $3 \mathrm{mg} / \mathrm{kg}$ of body weight) in mice for 5 days in non- infected/ non-treated mice ,infected/ treated mice and in infected/non- treated mice did not produced any significant effect on the integrity of the smooth muscles $(p>0.05)$ irrespective of the dosage regimens administered in this study.( Figure $4-7)$.

Histological sections of smooth muscle of the Ileum treated with Non -Infected /treated with $3 \mathrm{mg} / \mathrm{kg}$ and $6 \mathrm{mg} / \mathrm{kg}$ of artemether revealed normal cellular profile, hence no abnormality seen. 


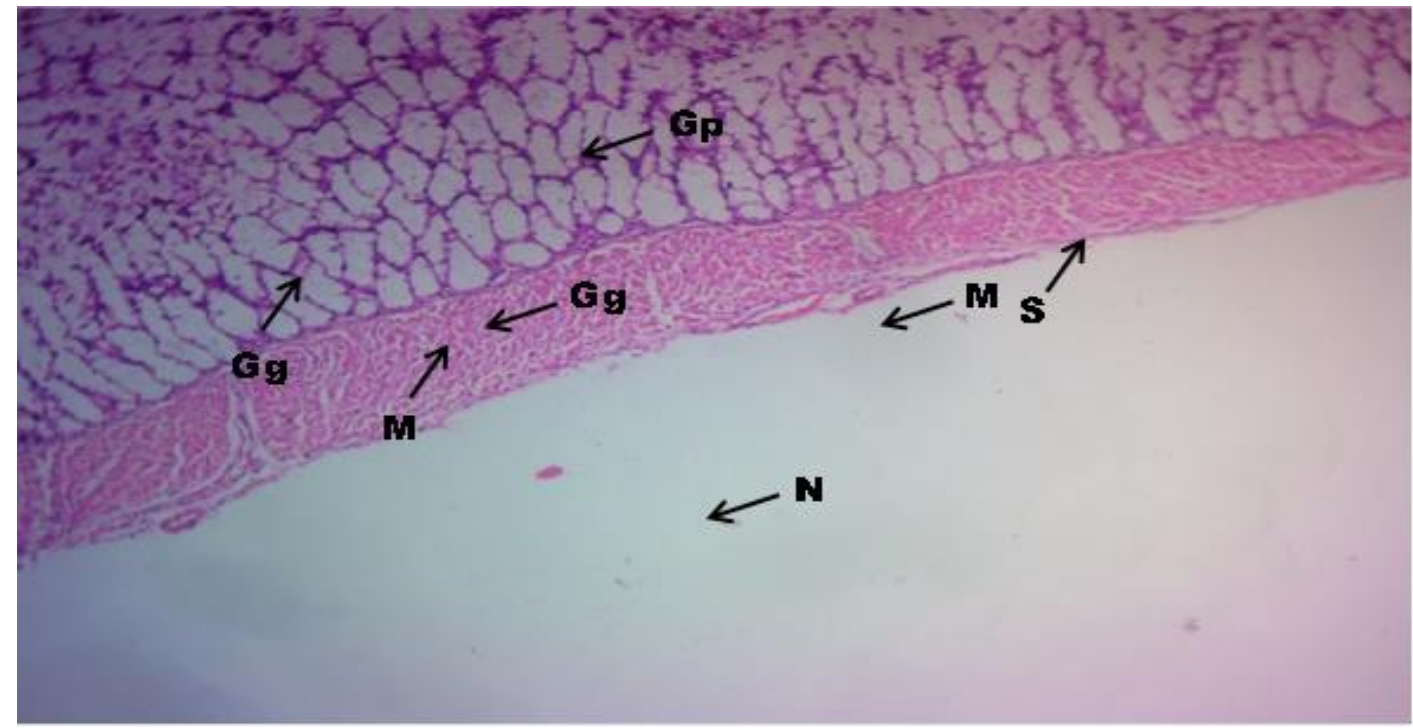

Figure 4 Photomicrographs of smooth muscle of the Ileum non-Infected and $6 \mathrm{mg} / \mathrm{kg}$ of artemether at mag. (x400) stained with H\& E method. Revealed normal cellular profile with no abnormality seen. Keys: Lumen (L), Nucleus (N), Gastric gland (Gg), Gastric pit (Gp), Muscularis mucosa (MM) and Serosa(S).

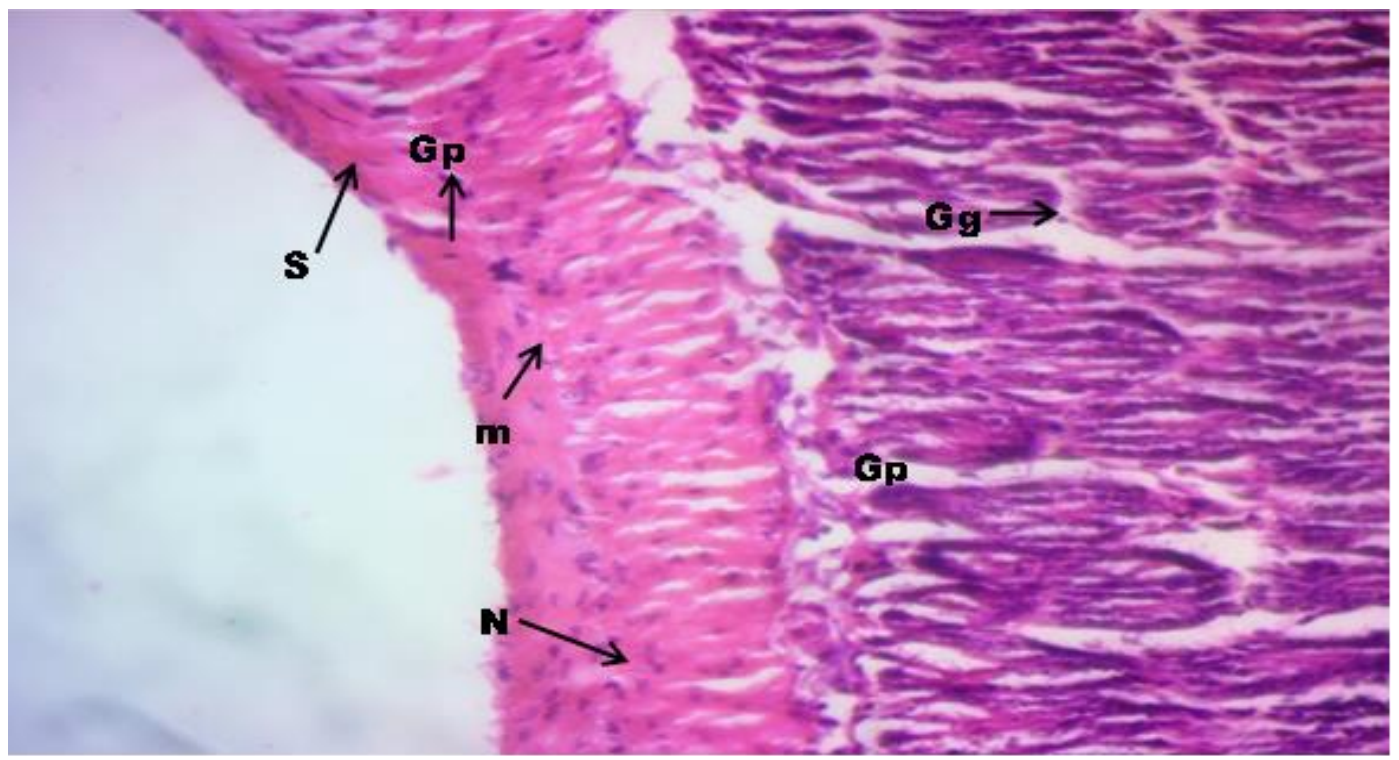

Figure 5 Photomicrographs of smooth muscle of the Ileum Infected with Plasmodium berghei berghei and non treated (Negative control) at Mag. (x400) stained with H\& E method. Lumen (L), Nucleus (N), Gastric gland (Gg), Gastric pit (Gp), Muscularis mucosa (MM) and Serosa(S).Revealed normal cellular profile. 


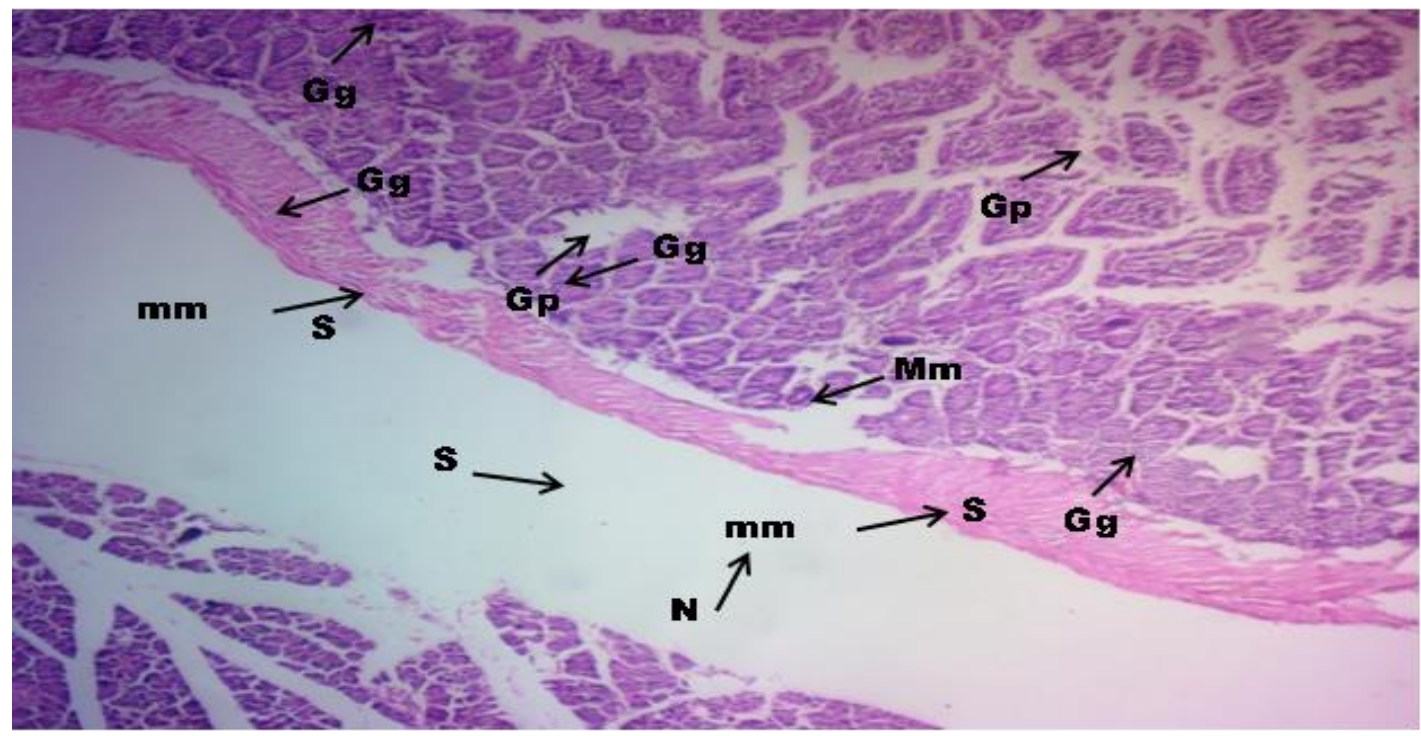

Figure 6 Photomicrographs of smooth muscle of the Ileum infected with P. berghei berghei and treated with $3 \mathrm{mg} / \mathrm{kg}$ of artemether at mag. (x400) stained with H\& E method. Revealed normal cellular profile, no abnormality seen.

\section{Keys: Lumen (L), Nucleus (N), Gastric gland (Gg), Gastric pit (Gp), Muscularis mucosa}

The results of this study revealed that, the control drug, acetylcholine in the dose range ( $\left.4 \times 10^{-8}-4.0 \times 10^{-4} \mathrm{M}\right)$, $\operatorname{oxytocin}\left(8.0 \times 10^{-10}-8.0 \times 10^{-6}\right)$, potassium chloride $\left(1.0 \times 10^{-3}-1.0 \times 10^{-1} \mathrm{M}\right)$, barium chloride $\left(8.0 \times 10^{-6}-8.0\right.$ $\mathrm{x} 10^{-2} 0$, each caused a marked concentration - dependent contractions of the isolated rat ileum and uterine muscle strips . In another study, artemether alone at a concentration of $\left(2.1 \times 10^{-6}-2.1 \times 10^{-2}\right) \mathrm{g} / \mathrm{ml}$ produced no contractile responses on the isolated rat ileum and uterine muscle strips within 30-60 minutes of drug-tissue contact in the organ bath containing tyrode solution (Ileum ), dejalon's solution (uterine muscle) . In some preparations it showed no response, while in others it produced slight phasic contraction when external calcium $\left(\mathrm{Ca}^{2+}\right)$ ion was introduced. The slight phasic contractile activity was abolished by verapamil $\left(5 \times 10^{-3} \mathrm{mg} / \mathrm{ml}\right)$. This observed results of no contractile responses when artemether was applied alone, was similar with reportt on chloroquine which produced no contractile responses when applied on the rat urinary bladder strip under baseline conditions ${ }^{22}$.

The antagonism by artemether in each instance, for example ( Ach. > Bacl > kcl) was non-competitive ,this is basically proven by the agonist -concentration response curves which were clearly displaced to the right in asymmetric non parallel fashion, with depressed maxima (Figure 2-3, Table 1 ). It had been an established principle that, contractile responses induced by acetylcholine and carbachol were influenced mainly by the stimulation of muscarinic receptors $\mathrm{s}^{22}$. On the other hand, the observed contractile responses, were reversibly abolished due to the introduction of zero Ca $2+$ in physiological solution.

$\mathrm{KCl}$-induced contractions are largely reported to be due to a depolarizing action on the plasmamembrane of the rat urinary bladder, as a result of which extracellular $\mathrm{Ca}{ }^{2}+$ influx occurs via voltage - dependent Ca ${ }^{2+}$ channels (VOCs); $22,23,24$; and 25.

Also, artemether $\left(2.1 \times 10^{-6}-2.1 \times 10^{-2} \mathrm{~g} / \mathrm{ml}\right)$ when applied alone and separately excited marked variable effects on rat uterine muscles strips : the effect of artemether $\left(2.1 \times 10^{-6} \mathrm{~g} / \mathrm{ml}\right)$ in non-pregnant rat uterus on oxytocin $(8.0 \times 10$ $10-8.0 \times 10^{-6}$ I.U.) induced contractions was markedly inhibitory ; these inhibition was significant $(\mathrm{P}<0.01-0.05),($ Figure 2)..This findings corroborated with report that artemether (48 $-480 \mathrm{ug} / \mathrm{ml}$ ) had no agonist. effects on the isolated uterine smooth muscles of both non-pregnant and pregnant rats, however the drug ( $24-240 \mathrm{ug} / \mathrm{ml}) \mathrm{reduced}$ oxytocin-induced contraction of uterine tissues concentration-dependently, particularly in pregnant uteri 12 . This observed results can further be justify based on earlier reports that, $\mathrm{KCl}$ - induced contractions were due to a depolarizing action on the plasmamembrane of the guinea pigs and rats isolated ileum, as a result of which extracellular $\mathrm{Ca}^{2+}$ influx occurs via voltage - dependent $\mathrm{Ca}^{2+}$ - Channels, ${ }^{23,22} ;{ }^{26}$ and the availability of $\mathrm{Ca}^{2+}$ is a basic determinant for smooth muscle contraction ${ }^{25}$, 26. The observed result of inhibition by artemether on agonists induced contractile responses were not inhibited by phentolamine ,and atropine.in the different set of study- which might likely suggest non-specific antagonism. The histopathological examination revealed no cellular abnormality seen in the smooth muscle profiles, hence artemether is relatively safe and might seldom present mild peri-muscular inflammations on body musculature. 


\section{Conclusion}

The results of this study show conclusively that artemether possessed great and safe pharmacological properties that justified its current use in the treatment of malaria as recommended by the World Health Organization. The results also revealed significant inhibited contractile responses induced by acetylcholine and potassium chloride on isolated ileal smooth muscle tissue in rats in a dose dependent manner with Emax of 12.6.mm; also Artemether significantly inhibited the contractions induced by barium chloride and oxytocin on uterine smooth muscle strips in rats in a dose dependent manner: all the observed results were independent of tissue specie variation.

Artemether seems to be acting via a non-specific receptor mechanism, interference with extracellular Ca ${ }^{2+}$ influx and possibly with mild interference with transmembrane ion fluxes by a non-specific processes, independent of animal species variation.

\section{Compliance with ethical standards}

\section{Acknowledgments}

The technical assistance of laboratory technologists Mr Nsikan Malachy and Ms. Rosemary Akpan is highly appreciated.

\section{Disclosure of conflict of interest}

There is no conflict of interest among the Authors.

\section{Statement of ethical approval}

All the animals received humane care and the study protocols were designed to comply with the Faculty of Pharmacy, University of Uyo ethical committee's guidelines for use of laboratory animals. Clearance was obtained in line with the 'Principle of Laboratory animal care' (of National Institute of Health-NIH Publication No. 85-123; 1996) guidelines [21].

\section{References}

[1] WHO / World Malaria Report. (2019). World Health Organisation.

[2] Bruce-Chwatt LJ. (1985). Recent Trends of Chemotherapy and Vaccination against Malaria. New lamps for old. British Medical Journal, 291, 1072-1076.

[3] WHO. (1986). Severe and Complicated Malaria Transmission. Royal Society of Tropical Medicine. And Gyg, 80 (suppl). 1-50.

[4] Gary HP, Michael HP, Northrop Jeffrey S and Ploypradith. (1998).Orally active, hydrolytically stable, semisynthetic, antimalarial trioxanes in the Artemisinin family. Journal of Medical Chemistry, 42(2), 300-304.

[5] Chen C. (2014). Development of antimalarial drugs and their application in China; a historical review.inf Dis Pov, 3(9), 3-9.

[6] Rosenthal PG. (2004). Antiprotozoal drugs in; Katzung BG(ed.) Basic and clinical Pharmacology. The McGrawHill Companies Inc Singapore, 864-85.

[7] Isaacson A and Sandow A. (1967). Quinine and Caffeine effects on 45 Camovements in frog Sartorius muscles, sartorius muscles J, Gen.Physiol, 50, 2109-2128.

[8] Huddart H. (1971) .The effect of quinine on tension development, membrane potentials and excitationcontraction coupling of crab skeletal muscle fibers. Journal of Physiology (London), 216, 214-257.

[9] Ebeigbe $\mathrm{AB}$ and Aloamaka C.P. (1982). Effects of Chloroquine on mechanical activity the rat portal vein microcirculation, 2, 151-159.

[10] Unekwe PC, Nwajie EE and Edafiogho IO. (1990).Effect of Chloroquine on rat Urinary bladder strip. Nig. Journal of physiological Sciences, 6(2), 109-113.

[11] Unekwe PC, Ogama JO, Chilaka KC and Okonkwo JC. (2007). Effect of Mefloquine on the mechanical activity of the Mouse isolated rectal smooth muscle.Nigeria. Journal of Physiol. Sciences, 22(1-2), 43-47. 
[12] Ejiofor JI, kwanashie HO and Anuka JA. (2006).Effects of Artemether on pregnancy related parameters in albino wistar rats, Journal of Pharmaceutical Sciences, 17, 97-11 1.

[13] Tologbonse AA, Unekwe PC, Mbagwu HOC, Udoh MO, Essien GE and Bello TE. (2018). The Effects of Artesunate on Isolated Ileum Smooth Muscle in Guinea pig Model Abstract in International Conference Proceedings of West African Society of Toxicology(WASOT),Uniabuja, 65.

[14] Ugian EA, Dasofun K, Nwangwa JN, Asuk AA, Akam MS, Ajing EN and Ugoanyanwu FU. (2013). Effect of artemisinin-based combination therapy on some selected Liver function indices in of pregnant wistar albino rats. Journal of applied pharmaceutical Sciences, 3(09), 152-154.

[15] Peters W.(1970). Chemotherapy and Drug Resistance in Malaria. London and New York Academic Press, 345391.

[16] Udobang JA, Nwafor PA and Okokon JE. (2010). Analgesic and Antimalarial Activities of Crude Leaf Extract a]nd Fractions of Acalypha Wilkesiana. Journal of Ethnopharmacology, 127, 373 - 378.

[17] Yakubu MT, Olajide AT and Akanji MA. (2009). Mode of cellular toxicity of aqueous extract of Fadogia agrestis (Schweinf. Ex Hiern) stem in male rat liver and kidney. Human and Experimental Toxicology, 28(8), 469-478.

[18] Unekwe PC, Nwajie EE and Edafiogho IO. (1990). Effect of Chloroquine on rat Urinary bladder strip. Nig. Journal of physiological Sciences, 6(2), 109-113.

[19] Nwafor PA and Okwuasaba FK. (2003). Anti-conceptive and Anti-inflammatory Effects of Methanolic Extract of Asparagus Pubescens Root in Rodents. Journal of Ethnopharmacology, 84, 125 - 129.

[20] Akpan J0. (2007). Effect of Drugs on Smooth Muscle Contractility in Experimental Animals; Drugs and Dilution Principles; Lecture Notes, 35-46.

[21] National Institute of Health-NIH Publication No. 85-123; 1996 )

[22] Bolton TB. (1979). Mechanism of Action of Transmitters and other Substances On Smooth Muscles. Physiology Review, 59, 606-718.

[23] Van Breemen C, Aronson P and Lutzenbiser R. (1977). Sodium-calcium interactions in mammalian smooth muscles. Pharmacology. Rev, 30, 167-208.

[24] Brading Al and Srieldon P. (1980). Evidence for Multiple Sources of Calcium for Activation of the Contractile Mechanism for Guinea pig Taenia coli on Stimulation with Carbachol. British Journal Pharmacology, 70, 229-240.

[25] Cauvin C, Lukeman S, Cameton J, Hwang O, Masheri K, Yamamori H and Van Breeman C. (1984). Theoretical bases for Vascular Selectivity of $\mathrm{Ca}^{2+}$ antagonists, Journal of Cardiovascular Pharmacology, 6, 5630 -5638.

\section{How to cite this article}

Tologbonse AA, Essien GE, Onwuka AN, Mbagwu HOC and Unekwe PC. (2020). Effect of artemether on the mechanical activities of isolated smooth muscles of non-pregnant uterus and ileum in mice and wistar rats. GSC Biological and Pharmaceutical Sciences, 11(3), 144-154. 